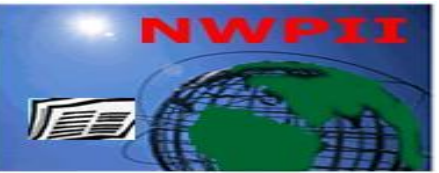

American Journal of

Biomedical Sciences

ISSN: 1937-9080

nwpii.com/ajbms

\title{
PSD-95 Interacts with Dopamine D1-Receptor: Functional Implication
}

\author{
Lingyong $\mathrm{Li}^{1}{ }^{*}$, Peihua Sun, Xuechu Zhen ${ }^{2 *}$ \\ ${ }^{\mathbf{1}}$ Department of Pharmacology, College of Pharmacy, Soochow University, Suzhou, China \\ ${ }^{2}$ State Key Laboratory of Drug Research, Shanghai Institute of Materia Medica, Chinese Academy of Sciences, \\ Shanghai, China \\ *Corresponding Authors: \\ Dr. Lingyong Li, Associate Professor \\ Department of Pharmacology \\ College of Pharmacy \\ Soochow University \\ Suzhou 215123, China \\ E-mail: lyli@mail.shcnc.ac.cn (LY Li), \\ Dr. Xuechu Zhen, Professor \\ ${ }^{1}$ Department of Pharmacology, \\ College of Pharmaceutical Sciences , \\ Soochow University \\ Suzhou, China \\ ${ }^{2}$ Department of Pharmacology, \\ Shanghai Institute of Materia Medica, \\ Chinese Academy of Sciences, \\ Shanghai, China \\ Tel.: +8651265880369 \\ fax: +8651265880369 \\ E-mail: zhenxuechu@mail.suda.edu.cn (Zhen XC)
}

Received: 8 March 2011; | Revised: 26 July 2011; | Accepted: 20 September 2011

\section{Abstract}

Dopamine (DA) system plays critical roles in many aspects of brain function. Abnormal dopaminergic activity is closely related to Parkinson's disease, schizophrenia, drug addiction and other neurological and psychiatric disorders. Postsynaptic density (PSD)-95, a scaffolding molecule, enriched at glutamatergic synapses, is found to have important functions in the modulation of clustering of several neurotransmitter receptor, adhesion molecules, ion channels, cytoskeletal elements and signaling molecules at postsynaptic areas. In this review we will highlight the role of PSD-95 in the interaction and regulation of DA receptors. We will also discuss the importance of PSD-95 in the regulation D1 and N-methyl-D-aspartate (NMDA) receptor functional coupling.

Keywords: PSD-95; dopamine receptor; trafficking. 


\section{Introduction}

The dopaminergic system comprises three principal neuronal pathways: the nigrostriatal, the mesocorticolimbic, and the tuberoinfundibular, which play important roles in many of brain function [1]. The dopamine (DA) elicits its roles via DA receptors. Five subtypes of mammalian dopamine receptors have been identified and are grouped into two classes: $\mathrm{D}_{1}$-like receptor (D1, D5) and D2-like receptor (D2, D3, and D4). In response to stimulation, perisynaptic DA receptors undergo a different pattern of agonist-induced internalization in comparison with extrasynaptic DA receptors [2]. Given the unique structure of postsynaptic density (PSD) and its roles in the modulation of neurotransmission [3], it is reasonable to speculate that the PSD may underlie the different response in DA receptor internalization between perisynaptic and extrasynaptic areas. PSD-95 protein is enriched in PSD, and the direct interactions of PSD-95 with NMDA, 5-HT receptors were found to be an essential mechanism for PSD-95-regulated function of these receptors [4]. Recent information indicates that PSD-95 is also physically associated with DA receptors and this association alters DA receptor signaling and DA receptor-NMDA receptor functional coupling [5-9]. PSD-95regulated other neurotransmitter receptors have been discussed in other excellent reviews $[4,10$, 11]. Here we will only discuss the interaction between PSD-95 and DA receptors and the functional coupling between DA and NMDA receptors.

\section{PSD-95, a major scaffolding molecule and neurotransmission modulator enriched at PSD}

PSD-95 is a prototypical scaffolding protein highly enriched in the PSD area and belongs to the membrane-associated guanylate kinase (MAGUK) family, which contains three PSD-95, Dlg, ZO-1 homology (PDZ) domains, a Src-homology-3 (SH3) domain, and a region homologous to yeast guanylate kinase (GK region) [4, 12]. It is now clear that the proteins of PSD-95 family not only act as anchor proteins, but also function as important modulators of signaling [3, 13]. PSD95 is located close to the postsynaptic membrane, and which can be labeled by PSD-95-specific antibodies from both the extracellular and cytoplasmic faces. The unique anatomical location makes it in a good position to interact with postsynaptic membrane proteins such as receptors, ion channels, cell adhesion molecules, and cytoplasmic proteins at the postsynaptic area. In this way, PSD-95 could regulate the surface delivery, endocytosis, subcellular location, subunit composition and even intrinsic functional properties of targeted proteins or receptors [4]. Moreover, abnormal PSD-95 expression has been implicated in Parkinson's disease and schizophrenia and is believed to contribute to abnormal neurotransmission in these diseases [14$16]$.

\section{PSD-95 interacts with dopamine receptors physically}

DA receptors are members of the G-proteincoupled receptor (GPCR) family. Abnormal dopaminergic activity is closely associated with Parkinson's disease, schizophrenia, drug addiction $[8,17,18]$. D1-like receptors are coupled to Gs/Golf, which stimulate adenylate cyclase to produce the intracellular second messenger cAMP, and regulate the protein kinase A (PKA)/dopamine and cAMP-regulated phosphoprotein-32 (DARPP32)/protein phosphatase 1 (PP1) pathway [18-22], whereas D2-like receptors are coupled to $\mathrm{Gi} / \mathrm{Go}$, resulting in the inhibition of adenylate cyclase.

Anatomically, the majority of D1 receptors are localized in both perisynaptic and extrasynaptic areas of medium spiny neuron $[23,24]$ and cortical pyramidal neurons [25-27]. Two studies reported that PSD-95 physically associates with DA receptors $[7,8]$. In PSD-95 and D1 receptor co-transfected HEK293T cells and in mouse and rat brains, PSD-95 is co-immunoprecipitated with D1 receptor. This is further supported by the data of using immunofluorescence confocal microscopy and special fluorescence resonance energy transfer (spectral FRET) assays in transfected HEK293 cells. Several protein-protein interaction motifs of PSD-95 such the PDZs, the $\mathrm{SH} 3$, and the GK domains are well characterized s 
[4]. A region not previously known to be involved in protein-protein interaction, the $\mathrm{NH}_{2}$ terminus of PSD-95, was first identified to interact with Src [28]. Similarly, the $\mathrm{NH}_{2}$ terminus of PSD-95 was found critical for the interaction with D1 receptor. Moreover, Sun et al. [8] further found that the PDZ domain is also required for this interaction. As to the D1 receptor, previous studies showed that intracellular loops and carboxyl tail of D1 receptor, containing putative protein-protein interaction domains, are important for intracellular signaling [29-31]. The interacting site of D1 receptor with PSD-95 is found to be mediated by the COOH-terminal tail of D1 receptor $[7,8]$. Of interesting, administration of the D1 receptor agonist, SKF38393, resulted in a transient increase in the association between D1 receptor and PSD95 both in cultured cells and in rat brain, This may indicate that the agonist-modulated conformation of D1 receptor could make the receptor more accessible for PSD-95 binding [8]. However, the precise mechanism underlined dynamic changes in PSD-95 and D1 receptor association and the pursuant functional implication upon D1 receptor stimulation is still unknown. In addition to D1 receptor, D2 and D5 receptors were also found constitute interactions with PSD-95 [8]. This may indicates a global role of PSD-95 interacting DA receptors.

\section{PSD-95 regulates D1 receptor recycling}

It was reported that disrupting the interaction between PSD-95 and D1 receptor enhances D1mediated behaviors. This indicates that functional significance of the interaction. Using genomewide microarray profiling of striatal transcripts from either genetic or pharmacological mouse models, PSD-95 was identified as a regulator of dopamine-mediated synaptic and behavioral plasticity [5]. For instance, in dopamine transporter (DAT), norepinephrine transporter (NET), and vesicular monoamine transporters 2 (VMAT2) mutant mice and in chronically cocaine-treated mice, PSD-95 protein level was found to be downregulated. At the synaptic level, the reduction of PSD-95 correlates with the enhanced long-term potentiation (LTP) in the fronto-cortico-accumbal glutamatergic synapses.
Targeted deletion of PSD-95 in mice enhances LTP, augments the acute locomotor-stimulating effects of cocaine, and prevents any further increase in locomotor response to cocaine following repeated administration. Two possible mechanisms could explain the PSD-95 on the regulation of psychostimulant responsiveness. First, PSD-95 may directly or indirectly associated with subtypes of dopamine receptors, which affects desensitization, trafficking, and signaling of dopamine receptors. Second, dopaminergic axon and glutamatergic axon may form a "synaptic triad" at postsynaptic dendritic spines in the striatum, which may be required for the converging and coordinating actions of the two afferent pathways. Lacking of PSD-95, which alters postsynaptic architecture, may change the interplay of the two systems, engaging the glutamate synapses to a state more responsive to DA modulation [5]. In PSD-95 knockout mice, both SKF81297, a selective D1 agonist, and amphetamine, an indirect dopamine agonist, elicited substantially larger and more prolonged locomotor activation [7]. These studies defined the inhibitory role for PSD-95 in D1 function and established an important role for PSD-95 in mediating the locomotor stimulant effects of both amphetamine and cocaine, two major drugs of abuse.

PSD-95 regulates D1 receptor surface expression and the intracellular trafficking. Like other GCPRs, the DA receptors are subject to desensitization, internalization and resensitization in response to agonist stimulation. Upon agonist stimulation, DA receptor is quickly desensitized, a process involving the receptor phosphorylation by protein kinases. The desensitized receptor is uncoupled from the cognate G-protein and internalized. The latter including the arrestinmediated recruitments of clathrin and the AP-2 complex to the activated receptors, and subsequent clathrin-mediated endocytosis [32]. The internalized receptors either go degradation in lysomes or recycle back to plasma membranes.

Previous work demonstrated that PSD-95receptor interaction plays an inhibitory role in the agonist-induced internalization of respective receptor including NMDA [33], $\beta 1$ adrenergic [34] and serotonin 5-HT2A receptors [35]. In the 
case of D1 receptor, it was reported that PSD-95 enhanced D1 receptor internalization. This was found to be mediated by the dynamin-dependent endocytic pathway [7]. However, PSD-95 only accelerated D1 receptor turnover rate by shortening the time necessary for internalized receptor to return to membrane, since the D1 receptor density is not changed [8]. It is known that receptor endocytosis of desensitized GPCR is an initial step in the resensitization process that requires ligand-receptor dissociation and receptor dephosphorylation [36, 37]. The recovery of receptors at the membrane has been attributed to the synthesis and insertion of more receptors and to the recycling of endocytosed receptors [38]. In Sun et al.'s study [8], co-transfection with PSD-95 did not alter D1 receptor protein synthesis, suggesting that PSD-95-accelerated D1 receptor recovery is independent of new receptor synthesis. However, the accelerated recovery of membrane D1 receptors was prevented by inhibition of the recycling pathway, indicating that receptor recycling is the predominant mechanism involved in the PSD-95-accelerated recovery of membrane D1 receptors following desensitization/ internalization [8]. Thus, PSD-95 enhanced plasma recovery of internalized D1 receptors, consequently, accelerating the D1 receptor resensitization. This is supported by the data showing that PSD-95 does not alter D1 receptor stimulation-mediated cAMP production and that PSD-95 and D1 co-expression results in an increased spontaneous internalization without change the density of plasma membrane D1 receptor in untreated cells [8].

It is note that in one report showed that PSD95 inhibits $\mathrm{D}_{1}$ receptor-stimulated cAMP production in HEK-293 cells co-transfected with monkey $\mathrm{D}_{1}$ receptor and PSD-95 [7], which is in disagreement with that observation by a recent study [8]. However, the two studies have some differences in experimental details such as agonists used (DA/SKF38393 vs SKF81297) and receptor clones (human vs rhesus monkey D1). These differences may underlie the discrepancy between the two reports.

Although PSD-95 does not alter D1 receptor density in plasma membrane, however, it is interested to note that co-expressing PSD-95 and D1 receptor results in re-distribution of PSD-95 in HEK293 cells. We recently found that that D1

receptor co-expression increased PSD-95 relocation to plasma membrane (Fig.1).
A

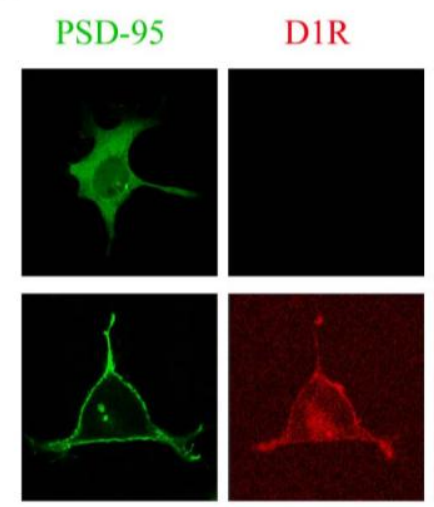

B

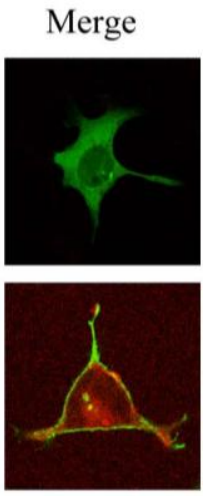

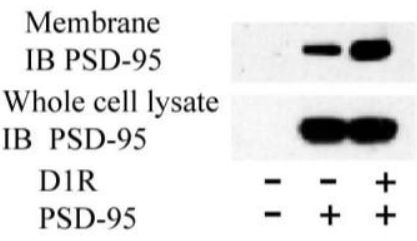

Membrane

IB PSD-95

Whole cell lysate

IB PSD-95

PSD-95 
permeability to $\mathrm{Ca}^{2+}$. Alteration of NMDA receptor-mediated $\mathrm{Ca}^{2+}$ influx is reported to be involved in schizophrenia and in excitotoxic neuronal death associated with brain disorders such as stroke, epilepsy, and trauma [40]. D1 receptor and NMDA receptor are co-localized in several brain structures, including caudateputamen, nucleus accumbens, hippocampus, and prefrontal cortex $[27,41,42]$. The balance between dopamineergic and glutaminergic interaction is largely mediated by the cross talk between the D1 receptor and the NMDA receptor in postsynaptic neurons. In addition to the direct interaction of D1 receptor and NMDA receptor, the downstream signal molecules mediated by D1 receptor is found to regulate NMDA receptor function [43, 44]. Activation of D1 receptor was found to enhance NMDA receptor currents [45] and to induce rapid trafficking of intracellular NMDA receptors to the postsynaptic membrane, resulting in an enhancement of NMDA receptor function [46]. In the other hand, NMDA receptors also reciprocally regulate D1 activity through direct protein-protein interaction [31]. D1 receptor physical interaction with NMDA receptor facilitates D1 receptor trafficking to the cell surface and inhibits D1 receptor internalization [47-49]. Thus, activation of NMAD receptors recruits D1 receptors to the plasma membrane, which, in turn, facilitates the activity and surface targeting of NMDA receptors, and results in a positive feed-back loop. Without this balance control, it might lead to concomitant overactivation of both D1 and NMDA receptor, endanger the neuronal integrity and trigger neurotoxicity [50, 51].

Recent information indicates that functional coupling between D1 and NMDA receptors depends on PSD-95. In addition to interaction with D1 receptor, PSD-95 interacting with NMDA receptor $[52,53]$ and regulating synaptic efficacy are well documented [3, 4, 54-58]. It was found that PSD-95 is required for D1 receptor-modulated NMDA receptor function, D1 receptor fails to modulate NR1a/NR2B receptor-mediated $\mathrm{Ca}^{2+}$ influx unless PSD-95 is co-expressed with D1 receptor and NR1a/NR2B receptor [6], suggesting that PSD-95 plays an important role in D1-NMDA receptor interaction and mutual modulation.
Moreover, PSD-95 was recently found to inhibit D1-NMDA receptor association and to attenuate the NMDA receptor-dependent enhancement on D1 signaling, this leads to the interruption of the D1-NMDA receptor positive feed-back loop [9]. PSD-95, D1, and NMDA receptors form a multiprotein complex, in which PSD-95 inhibits the physical association between D1 and NMDA receptors and thus modulates the functional interaction between the two receptors. PSD-95mediated inhibition may provide an effective means to weaken the constitutive D1-NMDA receptor association and to prevent overactivity of DA and/or glutamate [9].

\section{Conclusions and future direction}

Like other neurotransmitter receptors, D1-like and D2 receptors were also found to physically interact with PSD-95 in vitro and in vivo. The physically interaction is mediated through $\mathrm{NH} 2$ terminus of PSD-95, which is different from PDZ domain-mediated interactions between PSD-95 and other neurotransmitter receptors such as NMDA, 5-HT receptors. The underlined implication for the difference involved in structure domains of PSD-95 interacting receptors remains unknown. Functionally, PSD-95 accelerates the rate of D1 receptor recycling and resensitization without change the D1 receptor density in plasma membrane. This may represent a potential mechanism for the regulation of postsynaptic membrane D1 receptors in response to the pulse release of DA from nerve terminals. PSD-95 accelerates D1 receptor recycling back to the plasma membrane, thus shortening the time of desensitized/internalized receptor recovery. This process may be particular important for keeping adequate D1 receptor in the postsynaptic area in any given time to receive pulse DA release from presynaptic terminals.

Altered PSD-95 expression and distribution are documented in some neurological and psychotic disorders [14-16]. For instance, redistribution of PSD-95 was reported in levoDOPA-induced dyskinesia (LID) in PD animals [59]. Development of LID is believed to attribute to DA receptor supersensitization in PD followed DA replacement. How altered PSD-95 contributes 
to altered DA receptor functions in LID remained to be studied. Moreover, decreased PSD-95 expression was also reported in schizophrenia animal [16]. Accordingly, dysfunction of D1 receptor in prefrontal cortex was also documented in schizophrenia animals [60-63]. Further investigation need to be carried out to define the role of the altered PSD-95 in prefrontal cortical D1 receptor functional impairment in schizophrenia. In addition to D1 receptor, PSD-95 was also found to physically associate with another D1-like receptor, D5, and D2 receptor, the functional implications in physiology and diseases for this interaction are worth of further investigation.

PSD-95 also acts as a molecular brake for the positive D1-NMDA receptor feedback. Presence of PSD-95 in D1/NMDA receptor complex places a physical and functional barrier between the receptors by weakening their association. As a result, D1-mediated cAMP signaling enhanced by NMDA receptor stimulation is dampened, enhanced NMDA receptor activity stimulated by activation of D1 receptor is suppressed, and the positive D1-NMDA receptor feedback is ultimately antagonized. The future studies should focus on the precise mechanism and pathological implications for PSD-95-mediated D1 and NMDA functional coupling. Moreover, target to PSD-95 in modulation the interaction between PSD-95 and DA/NMDA receptor or other neurotransmitter receptors may provide a potential new strategy for drug discovery for neuropsychotic disorders.

\section{Acknowledgements}

This work was supported by 973 of the Ministry of Science and Technology of China (2009CB52201, 2011CB5C4403), and by grant from Natural Science Foundation of China (30900461, 30825042).

\section{References}

1. Civelli, O.; Bunzow, J. R.; Grandy, D. K. Molecular diversity of the dopamine receptors.
Annu Rev Pharmacol Toxicol, 1993, 33, 281 - 307. DOI: 10.1155/1993/37231

2. Dumartin, B.; Caillé, I.; Gonon, F. et al. Internalization of D1 dopamine receptor in striatal neurons in vivo as evidence of activation by dopamine agonists. J Neurosci, 1998, 18(5), 1650 - 1661

3. Kennedy, M. B. Signal-processing machines at the postsynaptic density. Science, 2000, 290(5492), $\quad 750-754 . \quad$ DOI: 10.1126/science.290.5492.750

4. Kim, E. J.; Sheng, M. PDZ domain proteins of synapses. Nat Rev Neurosci, 2004, 5(10), 771 - 781. DOI: 10.1038/nrn1517

5. Yao, W. D.; Gainetdinov, R. R.; Arbuckle, M. I. et al. Identification of PSD-95 as a regulator of dopamine-mediated synaptic and behavioral plasticity. Neuron, 2004, 41(4), 625-638. DOI:10.1016/S0896-6273(04)00048-0

6. Gu, W. H.; Yang, S.; Shi, W. X. et al. Requirement of PSD-95 for dopamine D1 receptor modulating glutamate $\mathrm{NR} 1 \mathrm{a} / \mathrm{NR} 2 \mathrm{~B}$ receptor function. Acta Pharmacol Sin, 2007, 28(6), $\quad 756-762 . \quad$ DOI:10.1111/j.17457254.2007.00557.x

7. Zhang, J.; Vinuela, A. ; Neely, M. H. et al. Inhibition of the dopamine D1 receptor signaling by PSD-95. J Biol Chem 2007, 282, $15778-15789$. 10.1074/jbc.M611485200

8. Sun, P.; Wang, J.; Gu, W. et al. PSD-95 regulates D1 dopamine receptor resensitization, but not receptor-mediated Gsprotein activation. Cell Res, 2009, 19(5), 612 - 24. DOI: $10.1038 / \mathrm{cr} .2009 .30$

9. Zhang, J.; Xu, T. X.; Hallett, P. J. et al. PSD-95 uncouples dopamine - glutamate interaction in the D1/PSD-95/NMDA receptor complex. $J$ Neurosci, 2009, 29(9), 2948 - 2960. DOI: 10.1523/JNEUROSCI.4424-08.2009

10. Neff R, A.; Gomez-Varela, D.; Fernandes, C. C. et al. Postsynaptic scaffolds for nicotinic receptors on neurons. Acta Pharmacol Sin 2009, 30 (6), $694-701$

11. Keith, D.; El-Husseini, A. Excitation control: balancing PSD-95 function at the synapse. 
Front Mol Neurosci, 2008, 1:4. DOI: $\underline{10.3389 / \text { neuro.02.004.2008 }}$

12. Cho, K. O.; Hunt, C. A.; Kennedy, M. B. The rat brain postsynaptic density fraction contains a homolog of the Drosophila discs-large tumor suppressor protein. Neuron, 1992, 9(5), 929 942. DOI:10.1016/0896-6273(92)90245-9

13. Sierralta, J.; Mendoza, C. PDZ-containing proteins: alternative splicing as a source of functional diversity. Brain Res Rev 2004, 47, $105-115$.

DOI:

10.1016/j.brainresrev.2004.06.002

14. Toro, C.; Deakin, J. F. W. NMDA receptor subunit NRI and postsynaptic protein PSD-95 in hippocampus and orbitofrontal ortex in schizophrenia and mood disorder. Schizophr Res, 2005, 80, 323-330. DOI: 10.1016/j.schres.2005.07.003

15. Kristiansen, L. V.; Meador-Woodruff, J. H. Abnormal striatal expression of transcripts encoding NMDA interacting PSD proteins in schizophrenia, bipolar disorder and major depression. Schizophr Res 2005, 78(1), 87 93. DOI: 10.1016/j.schres.2005.06.012

16. Kristiansen, L. V.; Beneyto, M.; Haroutunian, V. et al. Changes in NMDA receptor subunits and interacting PSD proteins in dorsolateral prefrontal and anterior cingulate cortex indicate abnormal regional expression in schizophrenia. Mol Psychiatry, 2006, 11(8), 737 - 747. DOI: 10.1038/sj.mp.4001844

17. Jaber, M.; Robinson, S. W.; Missale, C. et al. Dopamine receptors and brain function. Neuropharmacology, 1996, 35(11), 1503 1519. DOI: 10.1016/S0028-3908(96)00100-1

18. Missale, C.; Nash, S. R.; Robinson, S. W. et al. Dopamine receptor:From structure to function. Physiol Rev, 1998, 78(1), 189 - 225.

19. Lachowicz, J. E.; Sibley, D. R. Molecular characteristics of mammalian dopamine reception. Pharmacol Toxicol, 1997, 81(3), $105-113$.

20. Greengard, P. The neurobiology of slow synaptic transmission. Science, 2001, 294, 1024 - 1030.

DOI:

10.1126/science.294.5544.1024

21. Neve, K. A.; Seamans, J. K.; TranthamDavidson, H. Dopamine receptor signaling. $J$
Recept Signal Transduct Res, 2004, 24(3), $165-205$.

22. Bibb, J. A. Decoding dopamine signaling. Cell, 2005, 122(2), 153 - 155. DOI: 10.1016/j.cell.2005.07.011

23. Levey, A. I.; Hersch, S. M.; Rye, D. B. et al. Localization of D1 and D2 dopamine receptors in brain with subtype-specific antibodies. Proc Natl Acad Sci, 1993, 90(19), 8861 - 8865.

24. Hersch, S. M.; Ciliax, B. J.; Gutekunst, C. A. et al. Electron-microscopic analysis of D1 and D2 dopmaine-receptor proteins in the dorsal striatum and their synaptic relationships with motor corticostriatal afferents. J Neurosci, 1995, 15(7), 5222 - 5237.

25. Smiley, J. F.; Levey, A. I.; Ciliax, B. J. et al. D1 dopamine-receptor immunoreactivity in human and monkey cerebral-corrtexpredominant and extrasynaptic location in dendritic spines. Proc Natl Acad Sci , 1994, 91(12), 5720 - 5724.

26. Bergson, C.; Mrzljak, L.; Smiley, J. F. et al. Regional, cellular, and subcellular variations in the distribution of D-1 and D-2 dopamine receptors in primate brain. J Neurosci, 1995, 15(12), 7821 - 7836.

27. Sesack, S. R.; Carr, D. B.; Omelchenko, N. et al. Anatomical substrates for glutamatedopamine interactions: evidence for specificity of connections and extrasynaptic actions. Ann N Y Acad Sci, 2003, 1003, 36 - 52. DOI: 10.1196/annals.1300.066

28. Kalia, L. V.; Pitcher, G. M.; Pelkey, K. A. et al. PSD-95 is a negative regulator of the tyrosine kinase Src in the NMDA receptor complex. EMBO J, 2006, 25(20), 4971 - 4982. DOI:10.1038/sj.emboj.7601342

29. Lezcano, N.; Mrzljak, L.; Eubanks, S. et al. Dual signaling regulated by calcyon, a D1 dopamine receptor interacting protein. Science, 2000, 287, $\quad 1660$ - $1664 . \quad$ DOI: $\underline{10.1126 / \text { science. } 287.5458 .1660}$

30. Kim, O. J.; Ariano, M. A.; Lazzarini, R. A.; et al. Neurofilament interacts with the D-1 dopamine receptor to regulate cell surface expression and desensitization. J Neurosci, 2002, 22(14), 5920 - 5930.

C 2011 by NWPII. All rights reserved. 
31. Lee, F. J.; Xue, S.; Pei, L. et al. Dual regulation of NMDA receptor functions by direct protein-protein interactions with the dopamine D1 receptor. Cell, 2002, 111(2), $219-230$.

DOI:10.1016/S00928674(02)00962-5

32. Gainetdinov, R. R.; Premont, R. T.; Bohn, L. M. et al. Desensitization of $\mathrm{G}$ protein-coupled receptors and neuronal functions. Аnnu Rev Neurosci, 2004, 27, 107 -144. DOI: 10.1146/annurev.neuro.27.070203.144206

33. Roche, K. W.; Standley, S.; McCallum, J. et al. Molecular determinants of NMDA receptor internalization. Nat Neurosci, 2000, 4(8), 794 - 802. DOI: 10.1038/90498

34. Hu, L. A.; Tang, Y.; Miller, W. E. et al. Beta 1 -adrenergic receptor association with PSD95.Inhibition of receptor internalization and facilitation of beta 1-adrenergic receptor interaction with N-methyl-D-aspartate receptors. J Biol Chem, 2000, 275(49), 38659 - 38666 .

DOI: 10.1074/jbc.M005938200

35. Xia, Z.; Gray, J. A.; Compton-Toth, B. A. et al. A direct interaction of PSD-95 with 5HT2A serotonin receptors regulates receptor trafficking and signal transduction. $J$ Biol Chem, 2003, 278(24), 21901 - 21908. DOI: 10.1074/jbc.M301905200

36. Zhang, J.; Ferguson, S. S. G.; Barak, L. S. et al. Molecular mechanisms of $G$ proteincoupled receptor signaling: role of $\mathrm{G}$ proteincoupled receptor kinases and arrestins in receptor desensitization and resensitization. Recept Channels, 1997, 5(3-4), 193 - 199.

37. Trincavelli, M. L.; Tuscano, D.; Cecchetti, P. et al. Agonist-induced internalization and recycling of the human $\mathrm{A}(3)$ adenosine receptors: role in receptor desensitization and resensitization. J of Neurochem, 2000, 75(4), 1493 - $1501 . \quad$ DOI:10.1046/j.14714159.2000.0751493.x

38. Martin-Negrier, M. L.; Charron, G.; Bloch, B. Receptor recycling mediates plasma membrane recovery of dopamine D1 receptors in dendrites and axons after agonist-induced endocytosis in primary cultures of striatal neurons. Synapse, 2006, 60(3), $194-204$.

DOI: $10.1002 /$ syn.20296

39. Dingledine, R.; Borges, K.; Bowie, D. et al. The glutamate receptor ion channels. Pharmacol Rev, 1999, 51(1), 7 - 61.

40. Cull-Candy, S.; Brickley, S.; Farrant, M. NMDA receptor subunits: diversity, development and disease. Curr Opin Neurobiol, 2001, 11(3), 327-35. DOI: 10.1016/S0959-4388(00)00215-4

41. Gracy, K. N.; Pickel, V. M. Ultrastructural immunocytochemical localization of the $\mathrm{N}$ methyl-D-aspartate receptor and tyrosine hydroxylase in the shell of the rat nucleus accumbens. Brain Res, 1996, 739(1-2), 169 81. DOI: 10.1016/S0006-8993(96)00822-0

42. Cepeda, C.; Levine, M. S. Dopamine and Nmethyl-D-aspartate receptor interactions in the neostriatum. Dev Neurosci, 1998, 20(1), 1 18.

43. Snyder, G. L.; Fienberg, A. A.; Huganir, R. L. et al. A dopamine/D1 receptor/protein kinase A/dopamine-and cAMP-regulated phosphoprotein $\quad\left(\begin{array}{lll}\mathrm{Mr} & 32 & \mathrm{kDa}\end{array}\right) /$ protein phosphatase-1 pathway regulates dephosphorylation of the NMDA receptor. $J$ Neurosci, 1988, 18(24), 10297 - 303.

44. Wang, J.; O’Donnell, P. D-1 dopamine receptors potentiate NMDA-mediated excitability increase in layer $\mathrm{V}$ prefrontal cortical pyramidal neurons. Cereb Cortex, 2001, 11(5), $\quad 452-62 . \quad$ DOI: $10.1093 /$ cercor/11.5.452

45. Chen, G.; Greengard, P.; Yan, Z. Potentiation of NMDA receptor currents by dopamine D1 receptors in prefrontal cortex. Proc Natl Acad Sci, 2004, 101(8), 2596 - 600.

46. Dunah, A. W.; Standaert, D. G. Dopamine D1 receptor-dependent trafficking of striatal NMDA glutamate receptors to the postsynaptic membrane. J Neurosci, 2001, 21(15), 5546 - 5558.

47. Scott, L.; Kruse, M. S.; Forssberg, H. et al. Selective up-regulation of dopamine D1 receptors in dendritic spines by NMDA receptor activation. Proc Natl Acad Sci, 2002, 99(3), 1661 - 1664. 
48. Fiorentini. C.; Gardoni, F.; Spano, P. F. et al. Regulation of dopamine D-1 receptor trafficking and desensitization by oligomerization with glutamate N-methyl-Daspartate receptors. J Biol Chem, 2003, 278(22), 20196-20202. DOI: $10.1074 / \mathrm{jbc} . \mathrm{M} 213140200$

49. Pei, L.; Lee, F. J. S.; Moszczynska, A. et al. Regulation of dopamine D1 receptor function by physical interaction with the NMDA receptors. J Neurosci, 2004, 24(5), 1149 1158.

50. Choi, D. W. Glutamate neurotoxicity and diseases of the nervous system. Neuron, 1988, $1(8), \quad 623$ - 634. DOI: 10.1016/08966273(88)90162-6

51. Bozzi, Y.; Borrelli, E. Dopamine in neurotoxicity and neuroprotection: what do D2 receptors have to do with it? Trends Neurosci, 2006, 29(3), 167 - 174. DOI: 10.1016/j.tins.2006.01.002

52. Kornau, H. C.; Schenker, L. T.; Kennedy, M. B. et al. Domain interaction between NMDA receptor subunits and the postsynaptic density protein PSD-95. Science, 1995, 269(5231), 1737 - 1740. DOI: 10.1126/science.7569905

53. Niethammer, M.; Kim, E.; Sheng, M. Interaction between the $\mathrm{C}$ terminus of NMDA receptor subunits and multiple members of the PSD-95 family of membrane-associated guanylate kinases. J Neurosci, 1996, 16(7), $2157-2163$.

54. Migaud, M.; Charlesworth, P; Dempster, M. et al. Enhanced long-term potentiation and impaired learning in mice with mutant postsynaptic density-95 protein. Nature, 1998, 396(6710), 433 - 439. DOI: 10.1038/24790

55. Stein, V.; House, D. R. C.; Bredt, D. S. et al. Postsynaptic density-95 mimics and occludes hippocampal long-term potentiation and enhances long-term depression. J Neurosci, 2003, 23(13), 5503 - 5506.
56. Ehrlich, I.; Malinow, R. Postsynaptic density 95 controls AMPA receptor incorporation during long-term potentiation and experiencedriven synaptic plasticity. J Neurosci, 2004, 24(4), 916 - 927.

57. Beique, J. C.; Lin, D. T.; Kang, M. G. et al. Synapse-specific regulation of AMPA receptor function by PSD-95. Proc Natl Acad Sci, 2006, 103(51), 19535 - 19540.

58. Xu, W.; Schluter, O. M.; Steiner, P. et al. Molecular d issociation of the role of PSD-95 in regulating synaptic strength and LTD. Neuron, 2008, 57(2), 248 - 262. DOI: 10.1016/i.neuron.2007.11.027

59. Nash, J. E.; Johnston, T. H. Collingridge, G. L. et al. Subcellular redistribution of the synapseassociated proteins PSD-95 and SAP97 in animal models of Parkinson's disease and LDOPA-induced dyskinesia. FASEB J, 2005, 19(6), $583-585$.

60. Guo, Y.; Zhang, H.; Chen, X. et al. Evaluation of the antipsychotic effect of bi-acetylated 1stepholidine (1-SPD-A), a novel dopamine and serotonin receptor dual ligand. Schizophr Res, 2009, $115(1), \quad 41-49$. DOI: 10.1016/j.schres.2009.08.002

61. Goldman-Rakic, P. S.; Castner, S. A.; Svensson, T. H. et al. Targeting the dopamine D1 receptor in schizophrenia: insights for cognitive dysfunction. Psychopharmacology, 2004, 174 (1), 3 - 16. DOI: 10.1007/s00213004-1793-y

62. Castner, S. A.; Williams, G. V.; GoldmanRakic, P. S. Reversal of antipsychotic-induced working memory deficits by short-term dopamine D1 receptor stimulation. Science, 2000, 287, 2020-2022. DOI: 10.1126/science.287.5460.2020

63. Knable, M. B.; Weinberger, D. R. Dopamine, the prefrontal cortex and schizophrenia. $J$ Psychopharmacol, 1997, 11, 123 - 131. 